\title{
Research on problems and solutions of distributed generation metering system
}

\author{
Zhang Jiaming1,a,Cheng Yingying ,Chang Shiliang, Xiao Ji, Du jie , Zhou Feng \\ State Grid Chongqing Electric Power CO. \\ Electric Power Research Institute \\ Chongqing 401120, China; \\ e-mail:zjmkerry@163.com
}

Keywords: distributed generation, metering system, energy meter, power quality.

Abstract. Nowadays, along with the continuously promoting of economy and society development, the situation of energy becomes more and more grim. Distributed generation serves as a clean and renewable supply of electricity energy, has been an important supplement besides the normal thermal power generation for its characteristics such as clean, environmental and flexible. This thesis did research on its metering system combined with the operating characteristics of distributed generation, did analysis on the performance and problems exists according to the specificity of distributed generation metering system, and proposed feasible ways aiming at those case metering device fails to meet the demand.

\section{Introduction}

Distributed generation usually stands for relatively scatter and small renewable energy generation, which includes photovoltaic, wind electricity, small hydropower, biomass power and gas turbine and generation of other similar energy forms. The grid connected operation of distributed generation could effectively alleviate the problem of energy short and benefits in energy structure optimization, environment pollution decrease and greenhouse effect lightening. However, for the characteristic of easily restricted by natural conditions, the controllability of distributed generation trends to be low, as a result, power grid is facing to new challenges like harmonic pollution, power quality and flow variation caused by grid connecting load characteristic of distributed generation. Take the fact that settlement of distributed generation involve power supply enterprise, distributed generation enterprise and relative government apartments, this thesis take low voltage distributed generation as study object, do analysis on the influence of metering system caused by factors above and propose feasible improve methods.

\section{Specificity of metering system of distributed generation}

Recently metering system of low voltage distributed generation is similar to normal ones, which is formed by transformer, energy meter and security circuit, usually placed on the division point of property. However, caused by the specialty of distributed generation, the demand of their metering system have many differences from normal ones, which is mainly concluded as below:

a) Recently, to realize the target of energy saving and emission reduction, major districts has carried out favorable policy or clean energy subsidies. As is known, distributed generation has two grid connecting modes: generation and load. From the view of avoid subsidies extraction by sending energy to grid for multi times, the metering system of distributed generation should be able to meter energy both generation and consumption and eradicate the probability consumption energy return to generation wire from structure level.

b) Distributed generation has grid connecting load characteristic, which makes it may work as generation or load. In other words, when natural condition reaches the demand of generation, it works as generator and sends energy to grid, otherwise it works as load and consume energy form grid, this characteristic demands the metering system be able to meter energy in both direction. 
c) The origin form of distributed generation always refers to high frequency alternation current or direct current, for the demand of grid connection, we need to acquire $50 \mathrm{~Hz}$ sinusoidal AC power by application of converter or inverter, in this period harmonic wave component and direct current component will be inevitably injected into grid connecting energy. Take metering accuracy and optimization of energy quality into consideration, distributed generation metering system is demand to collect and meter harmonic wave and direct current components.

\section{Configuration of distributed generation metering system}

A kind of common distributed generation metering system is as shown in Fig.1:

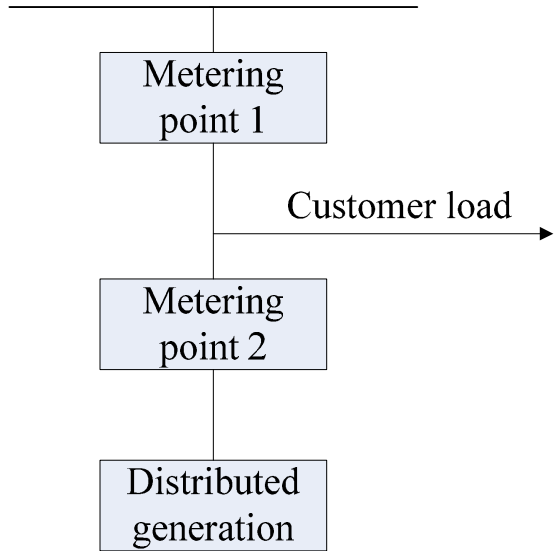

Fig.1 Common sturcture of distributed generation metering system

In the view of bidirectional metering, we can simply set two sub-metering point to realize the object. However, this system structure has not take subsidies extraction into consideration, a typical example of system refit is as shown in Fig.2:

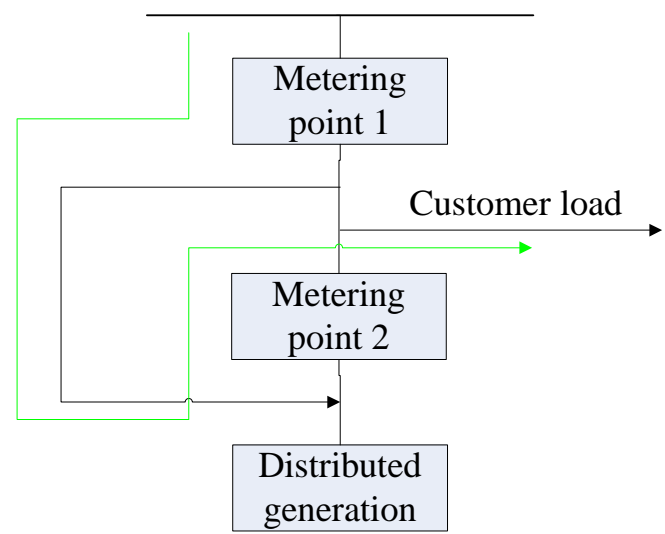

Fig.2 An example of refitted metering system

Make a comparison and we can find that when grid energy blows to customer load in the way green lines guides, this part of energy could still be considered as generated energy, which means that generation customers can easily extract grid connecting subsidies and which will do harm to the economical efficiency of power grid.

After analysis, we find that the leak is caused by lack of private metering point of customer load, as a solution, we can take use of three point metering method, which is shown as Fig.3. In the structure of metering system, metering point 1 takes charge of metering of energy sent to grid and taken from grid, metering point 2 takes charge of metering of total energy generated of distributed generation, while metering point 3 meters energy customer load consumes. 


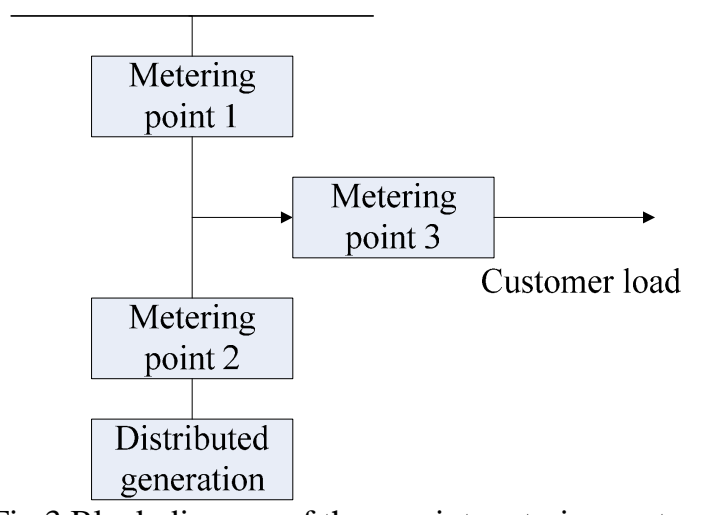

Fig.3 Block diagram of three point metering system

\section{Research on metering method of energy metering in both direction}

Since distributed generation has the characteristics of intermittency and stochastic, it may work in generation mode or load mode. However, when it works as generator and send energy to grid, the grid connecting current is decided by its installed capacity, which usually keeps in a high level, meanwhile when it works as a load and take energy from grid, the grid connecting current is decided by energy needed by its load, which is far less than installed capacity. According to the investigation, almost all recent metering devices are configured under generation mode, the problem reflect into fact is low metering accuracy when distributed generation works in load mode, in some extreme examples, metering devices is unable to recognize load mode of distributed generation at all.

Take a $220 \mathrm{kV} / 600 \mathrm{~A}$ wind power plant as example: wind power plant installed 56 fans whose rated capacity is $2.5 \mathrm{MW}$, the gateway installed two energy meters in same time: meter A with specification 5(6) $A$ and meter B with specification 0.3(6) $A$. Consider the situation that wind power plant consumes energy from grid, the energy taken is mainly consumed by keeping or initiating fans, the power of fan varies according to conditions like wind direction, wind speed and rotating speed, and usually appear in the variation of $0 \sim 20 \mathrm{~kW}$, for convenience, this thesis take the average value $10 \mathrm{~kW}$ as the initiating power of a fan to do calculation:

When a fan initiates, the grid connecting current is:

$$
I_{d}=10 \mathrm{~kW} / 220 \mathrm{kV} \approx 0.04545 \mathrm{~A}=45.45 \mathrm{~mA}
$$

After the transformation of current transformer, the current flow through energy meter is

$$
I_{m}=45.45 m A /(600 / 5)=0.379 m A
$$

By this time, to meter $\mathrm{A}$, whose starting current is $5 m A$, it can normally meter the energy when at least 14 fans initiate in the same time, while meter $\mathrm{B}$, whose starting current is $0.3 \mathrm{~mA}$ need only 1 fan's initiation to realize accurate metering.

To analysis the difference between metering performances of them, we install meter A and meter $\mathrm{B}$ on the same metering point, and compare their data record after 3 months, which is as shown in Table 1:

\begin{tabular}{|c|c|c|c|c|c|}
\hline & $\begin{array}{l}\text { Starting } \\
\text { data }(k W \cdot h)\end{array}$ & $\begin{array}{l}\text { Ending } \\
\text { data }(k W \cdot h)\end{array}$ & $\begin{array}{l}\text { Metering } \\
\text { rate }\end{array}$ & $\begin{array}{l}\text { Energy } \\
\text { data }(k W \cdot h)\end{array}$ & $\begin{array}{l}\text { Difference } \\
\text { rate }^{(\%)}\end{array}$ \\
\hline $\begin{array}{l}\text { Meter A } \\
\text { (generation) }\end{array}$ & 0.00 & 0.85 & \multirow{4}{*}{26400} & 224400 & \multirow{2}{*}{0.92} \\
\hline $\begin{array}{l}\text { Meter B } \\
\text { (generation) }\end{array}$ & 0.00 & 1.08 & & 285120 & \\
\hline $\begin{array}{l}\text { Meter A } \\
\text { (load) }\end{array}$ & 0.00 & 180.97 & & 47776080 & \multirow{2}{*}{27.06} \\
\hline $\begin{array}{l}\text { Meter B } \\
\text { (load) }\end{array}$ & 0.00 & 182.63 & & 48214320 & \\
\hline
\end{tabular}

Table 1 Data recorded by energy meters A and B 
According to the analysis, when metering generation energy, both meters could keep high accuracy, the difference rate is less than $1 \%$. However, when metering load energy, the difference rate between two meters is as large as $27 \%$, which is in line with the metering threshold value of them, which proves the necessity and correctness of wide range metering method.

\section{Research on harmonic wave metering performance}

The characteristic that harmonic wave be similar with normal energy is sinusoidal pattern, as a result the metering of harmonic wave could be calculated by energy metering method, and by this way we can analysis whether operating metering devices are able to meter harmonic wave accurately.

To an electric signal contains $H$ harmonic wave components, its signal of voltage and current can be expressed as below:

$$
\begin{aligned}
& u(t)=\sum_{k=0}^{H} u_{k}(t)=\sum_{k=0}^{H} u_{k} \sin \left(\omega_{k} t+\theta_{k u}\right) \\
& i(t)=\sum_{k=0}^{H} i_{k}(t)=\sum_{k=0}^{H} i_{k} \sin \left(\omega_{k} t+\theta_{k i}\right)
\end{aligned}
$$

In the formula, $H$ stands for the maximum number of harmonic wave, $u_{k}, i_{k}$ refers to the maximum value of voltage and current of the $k$ harmonic wave, while $\theta_{k u}$, $\theta_{k i}$ refers to the phase angle of the $k$ harmonic wave, $\omega_{k}=k w_{1}$ refers to the angle frequency of the $k$ harmonic wave, thus we get the expression of active power:

$$
P=\frac{1}{T} \int_{0}^{T} p(t) d t=\frac{1}{T} \int_{0}^{T} u(t) i(t) d t
$$

Take use of fast Fourier algorithm, and we get:

$$
P=\frac{1}{H} \sum_{k=1}^{H} u(n) \cdot i(n)
$$

Thus we get the total dot products of instantaneous power:

$$
P=\frac{1}{H} \sum_{d=0}^{H-1} u_{k}(n) \cdot i_{k}(n)=\frac{U_{k} I_{k}}{H} \sum_{d=0}^{H-1} \sin \left(\frac{2 \pi}{N} d+\theta_{a k}\right) \sin \left(\frac{2 \pi}{N} d+\theta_{b k}\right)
$$

By observing the astringency of total dot products of power under different value of $H$, we find that when $H$ is not less than 3, the error of total dot products has strong astringency and the convergence value is 0 . Which is to say that ensure there are at least 3 sampling point in each period of harmonic wave is necessary to realize accurate metering of harmonic wave.

$$
f_{s} \geq 3 H f_{0}
$$

According to our investigation, the sampling rate of most energy meters already installed is $12.8 \mathrm{kHz}$ or $6.4 \mathrm{kHz}$, which means that the number of sampling points during a period of working frequency is 256 or 128 , and the maximum order of harmonic wave accurately metered is 85 or 42 . As for common distributed generation harmonic wave tend to be weak when the order becomes bigger than 30 , we can say that operating metering devices are able to accurately meter the harmonic wave energy under the working frequency of $50 \mathrm{~Hz}$.

\section{Conclusion}

Along with the implement of energy conservation and emission reduction, it is certain that the number and capacity of distributed generation would be rapidly increased and metering problems would cause more and more attention from enterprise field and research field. This thesis combined the special demand of distributed generation metering system, did analysis from views of metering point design, wide range metering method in both direction, analysis on metering performance of harmonic wave and so on, figured that by using three point metering method we can avoid subsidies 
extraction, by making use of wide range energy meter we can improve the accuracy of metering system of distributed generation and metering devices in operation has been able to meter harmonic wave energy.

\section{References}

[1] Peigang Y, Tao Z. The influence to metering caused by distributed generation[J]. Dual Use Technologies \& Products, 2016(14).

[2] Zhan S,Huiyong H, Jinyong L. Bidirectional Metering Issues of User-Side Microgrid and User with Distributed Generation[J]. Southern Power System Technology,2015,9(4):14-21.

[3] Chunqiang Z, Jinghao L, Ding, Y. Research on the effect of the distributed power grid-connected load property on electric energy metering $[\mathrm{J}]$. Electrical Measurement \& Instrumentation,2016,53(8):75-80.

[4] Shufang Y, Xiaodong Z, Guofu Z, et al. Research on Measuring Technology of Electrical Capacity Generated by Distributed Supply[J]. Electrical Measurement \& Instrumentation,2014(s1).

[5] Shen T, Weihua L. Research on energy metering project of grid-connected distributed generatiaon[J].Electronic Technology \& Software engineering. 2015(23):242.

[6] Mengwei W, Yang Y. Analysis of Bidirectional Power Energy Measurement for Distributed Generation[J]. Electrotechnics Electric,2013(5):15-17.

[7] Abdel-Majeed A, Tenbohlen S, SchöLlhorn D, et al. Meter placement for low voltage system state estimation with distributed generation[C]// International Conference and Exhibition on Electricity Distribution. 2013:0640-0640.

[8] Kumar A, Srivarsha S. Intelligent Metering System in Integrated Power Generation \& Distribution system of a Steel Complex[C]// Joint International Conference on Power System Technology and IEEE Power India Conference, 2008. Powercon. IEEE, 2008:1-8.

[9] Sui H B, Sun Y, Lee W J, et al. Advanced Metering Infrastructure for Distributed Generation Energy Cooperation Management[J]. Applied Mechanics \& Materials, 2012, 229-231:1081-1084. 